\title{
Research Paper \\ Content Analysis of the Topics of Ageing-related Theses at the University of Social Welfare and Rehabilitation Sciences in Iran
}

\author{
Robab Sahaf ${ }^{1} \odot$, Hamid Reza Khankeh ${ }^{2} \odot$, Yadollah Abolfathi Momtaz ${ }^{1,3}{ }^{\oplus},{ }^{*}$ Arya Hamedanchi ${ }^{1} \odot$
}

1. Iranian Research Center on Aging, Department of Aging, University of Social Welfare and Rehabilitation Sciences, Tehran, Iran.

2. Research Center in Emergency and Disaster Health, University of Social Welfare and Rehabilitation Sciences, Tehran, Iran.

3. Malaysian Research Institute on Ageing (MyAgeing), Universiti Putra Malaysia, Serdang, Selangor, Malaysia.

\begin{tabular}{|c|c|}
\hline $\begin{array}{l}\text { Use your device to scan } \\
\text { and read the article online }\end{array}$ & 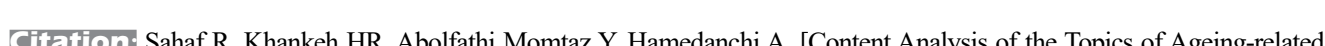 \\
\hline arista & $\begin{array}{l}\text { Theses at the University of Social Welfare and Rehabilitation Sciences in Iran (Persian)]. Iranian Journal of Ageing. 2018; } \\
\text { 13(3):300-311. https://doi.org/10.32598/SIJA.13.3.300 }\end{array}$ \\
\hline 口irtsts & doi': https://doi.org/10.32598/SIJA.13.3.300 \\
\hline
\end{tabular}

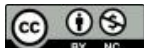

Funding: See Page 310

Received: 19 May 2018

Accepted: 22 Aug 2018

Keywords:

Gerontology, Geri-

atric medicine, Dis-

sertation, Research, Iran

\section{A B STRACT}

Objectives "Ageing" has created challenges for societies, particularly in developing countries. In this regard, the "Research Agenda on Ageing for the $21^{\text {st }}$ century" (RAA-21) has been prepared and published through a joint project of the "United Nations Program on Ageing" and the "International Association of Gerontology and Geriatrics." The University of Social Welfare and Rehabilitation Sciences is the first university in Iran that has admitted students in Gerontology, and currently has the largest number of students studying the subject of "Ageing." The current study aims to compare the topics of dissertations on ageing in the University with the priorities of RAA-21, because no similar study has been conducted at the University so far.

Methods \& Materials total of 248 dissertations and proposals on "Ageing" were included in this study. The titles were categorized into three levels (priority, research area, and specific topic) with a deductive content analysis approach using RAA-21 guidelines. The results were qualitatively described and compared with RAA21 priorities.

Results The fourth and fifth priorities of RAA-21 ("healthy ageing" as well as "biology and diseases") were identified as the most common priorities in the dissertations of both the University and the Gerontology Department (39.9\% and 21\%, respectively). The second priority of RAA-21 ("material security") had the least number of dissertations (3.3\%). With respect to "research areas," the highest number of dissertations was conducted in the "physical and mental function"(21.8\%) and then "biomedical" and "healthy ageing" (19\% each) subcategories. "Macro-societal changes and development" and "poverty" subcategories had the least number of dissertations $(0.0 \%$ and $0.4 \%$, respectively).

Conclusion distribution of dissertation topics conducted on "Ageing" at the University does not match with the priorities of RAA-21. As a descriptive study cannot present a certain causal relationship, an investigation into the reason for the differences is suggested for further studies. Moreover, it is also useful to prepare the national priorities for research on "Ageing," using need assessment and RAA-21 as guidelines.

\section{* Corresponding Author:}

Arya Hamedanchi, PhD Candidate

Address: Iranian Research Center on Aging, Department of Aging, University of Social Welfare and Rehabilitation Sciences, Tehran, Iran.

Tel: +98 (21) 22410399

E-mail: doctorarya@yahoo.com 


\section{Extended Abstract}

\section{Objectives}

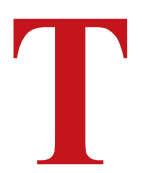

he increasing trend in longevity and number of elderly people over the past decades have created different needs for various countries [8]. In this regard, attention to the gerontology science has also increased around the world, and research has been recognized as one of one of the main foundations of ageing-related policies [10]. Of the important questions raised is that, considering the needs of societies, what are the research priorities in the field of ageing? and in each of the areas, what issues need to be paid more attention to? To answer these questions, United Nations Programme on Ageing (UNPoA), and International Association of Gerontology and Geriatrics (IAGG) developed Research Agenda on Ageing for the $21^{\text {st }}$ Century (RAA-21) [11].

Iran also has already affected by the aging phenomenon. Structural changes in the age groups of the Iranian population are underway requiring special research and policy [12]. Therefore, it is necessary to pay proper attention to research in the field of gerontology. University of Social Welfare and Rehabilitation Sciences (USWRS) is the leading university in this field, and accept students at various degrees, such as MSc., MPH and $\mathrm{PhD}$. However, there has not been a study on evaluating the topics of ageing-related theses at this university so far. In this regard, this paper aims to evaluate the topics of aging-related theses at USWRS based on RAA-21 criteria.

\section{Methods and Materials}

First, we referred to the Persian portal of the central library of the University and the theses related to Ageing were extracted. Then we referred to the education department and a list of proposals from 2014 onwards were gathered. Those proposals not included in the list of extracted theses were added to the study. Finally, the topics of 248 theses and proposals were examined. Content analysis using deductive approach was used to study and categorize the topics. The classification presented in RAA-21 was used as an initial basis, and then the results evaluated. In RAA-21, there are 109 specific topics for aging-related research, in total. Each of them has been included in one of 12 critical research areas, where these areas have been categorized into five major priorities [11]. The topics of study theses were evaluated with respect to these three factors.

\section{Result}

Of 248 theses reviewed, 169 had been defended and delivered, and 79 had been submitted for defense and were under evaluation. The first thesis related to the ageing found in the library was for 1998, and the last proposal approved at the time of this study was for July 2017. The largest number of completed theses was for 2015-2016, and the highest number of ongoing proposals was for $2016(n=44)$. The highest number of submitted theses and proposals belonged to graduate students (62.5\%), and then MPH (19\%) and PhD students $(18.5 \%)$. The most of study theses and proposals $(37.1 \%)$ were for the Department of Gerontology. The second and third rank were for the Department of Nursing (22.8\%) and Department of Rehabilitation Management (7.3\%).

In terms of major priorities, the most common and attractive research topics in all theses and proposals were "basic biological mechanisms and age associated diseases" (39.9\%) and "determinants of healthy ageing" $(21 \%)$. The lowest attractive topic was "current practices and options for maintaining material security in old age" $(3.3 \%)$. In terms of critical research areas, the most common research areas in the entire university was related to the "physical and mental functioning" (21.8\%), followed by "healthy ageing," and "biomedical" (19\%). In terms of covered specific topics, the most common topic was about "mental health" $(11.6 \%)$, followed by "research methodologies" $(6.2 \%)$, and "prevention and effective intervention" (5.8\%). In total, of 109 specific topics presented by RAA-21, 57 topics in study theses were examined.

\section{Conclusion}

Based on the available studies in literature, the current study is the first study that examines the topics of theses related to ageing in Iran. The results of the study indicate that the number of theses related to ageing has grown considerably in recent years. Three top research priorities in RAA21 were related to social, economic, and developmental issues, while it was found out that these priorities had not attracted the authors of theses and proposals in our study. Instead, priority 4 (determinants of healthy ageing) and 5 (basic biological mechanisms and age associated diseases) were the most attractive topics in all departments, including Department of Gerontology. Thus, there is a difference between research priorities mentioned in RAA-21 and those of USWRS. This study had a descriptive aspect and does not explain the reason for this difference. It is suggested that this difference be investigated in future studies, and by taking 
into account the existing international guidelines and local needs assessments, the priorities of ageing-related research at national level be addressed.

\section{Ethical Considerations}

Compliance with ethical guidelines

In this study, in order to maintain the principles of research ethics, the name of the students and theses were confidential.

\section{Funding}

This article is based on research project No. 1565 at the Iranian Research Center on Aging, University of Social Welfare and Rehabilitation Sciences, Tehran, Iran.

\section{Conflict of interest}

The authors declared no conflict of interests.

\section{Acknowledgements}

The authors of the article appreciate the collaboration of Dr. Fadaei Vatan and other professors and colleagues of the Department of Gerontology, Mrs. Omidvar and Khorshidi, Shahshahani and her colleagues, including Mrs. Sabour and Chardoolli, as well as Dr. Delbari and Mrs. Roostaei. 


\title{
تحليل محتواى عناوين يايان نامههاى مرتبط به سالمندى در دانشكاه علوم بجزيستى و توانبخشى
}

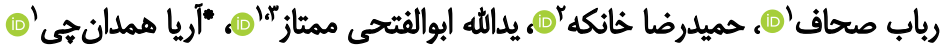 \\ 1- مركز تحقيقات سالمندى، كروه سالمندى، دانشكاه علوم بهزيستى و توانبخشى، تهراني، ايران.

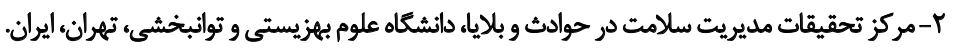

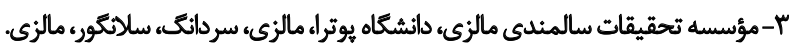

\section{حكSי}

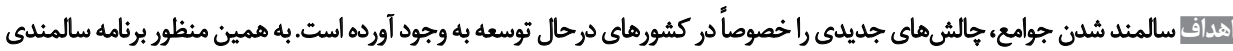

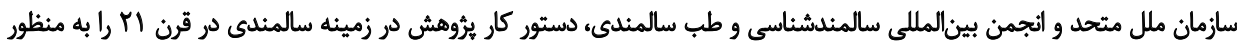

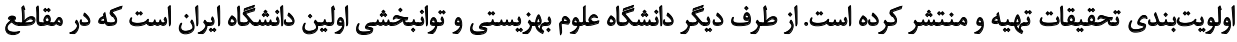

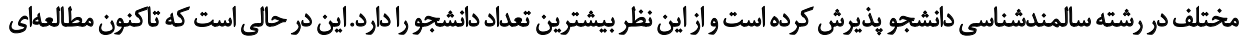

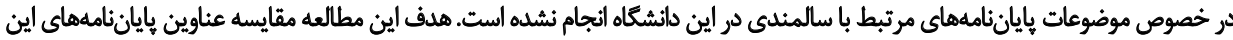

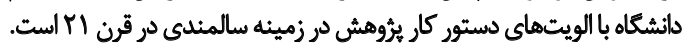

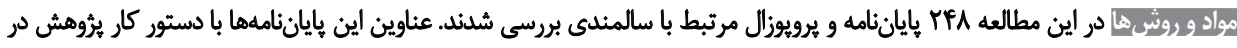

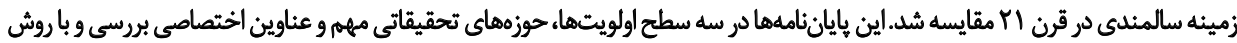

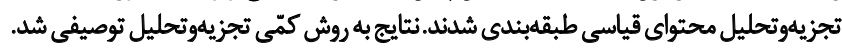

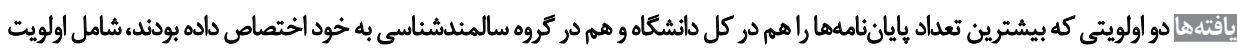

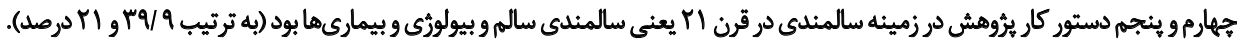

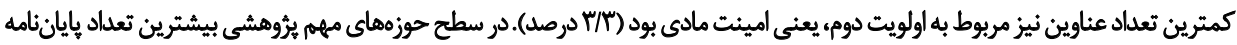

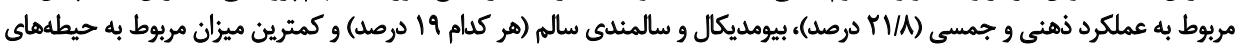

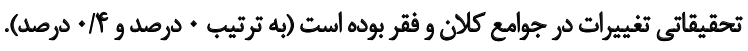

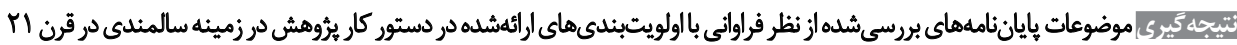

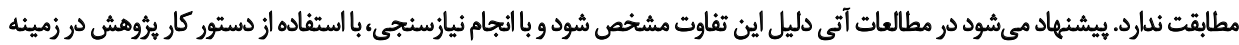

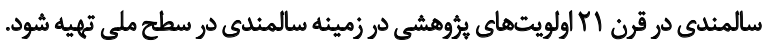

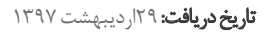

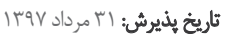

بيرى در بين انسانها يخش شد [ب]. در كشور ايران برداختن به به روند

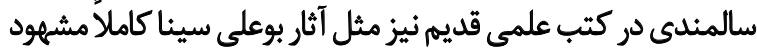

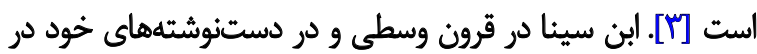

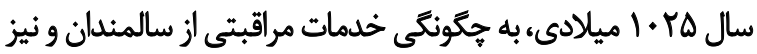

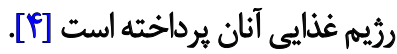

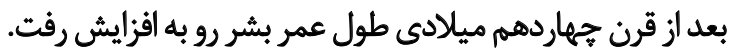

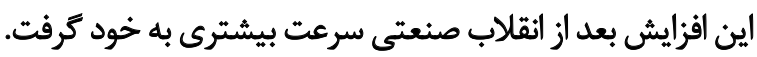

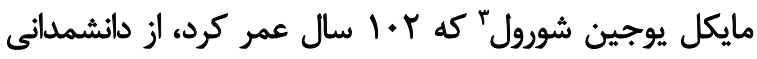

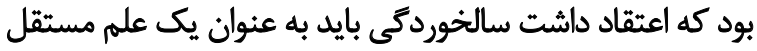


ساختارى دركزوههاى سنى جمعيت ايران در حال شكل خيرى است

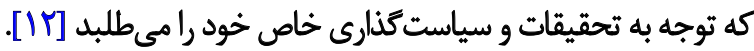

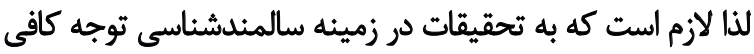

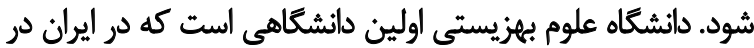

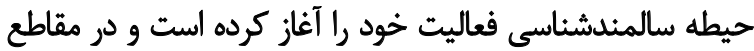

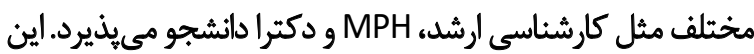

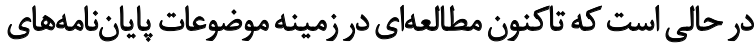

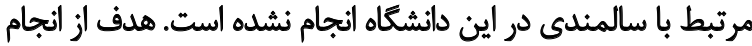

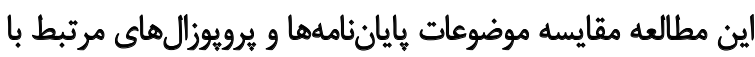

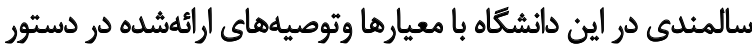

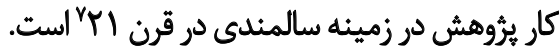

$$
\text { روش مطالعه }
$$

در اين مطالعه كه به منظور بررسى عناوين عاياننامههاي مرتبط

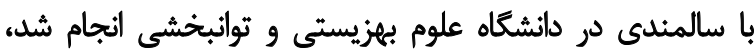

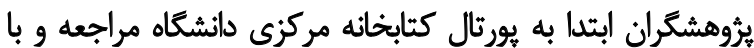

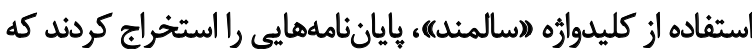

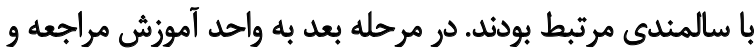

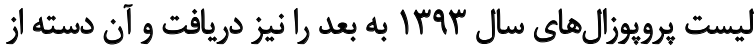

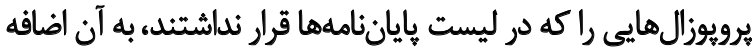

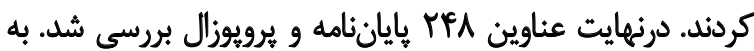

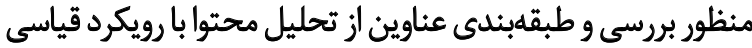

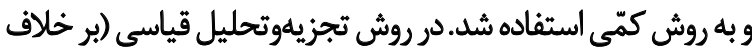

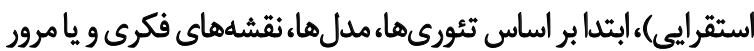

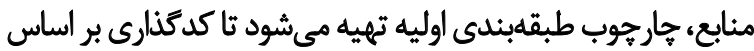

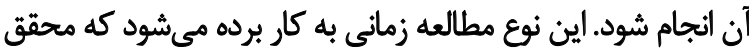

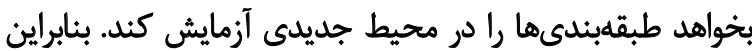

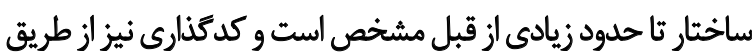

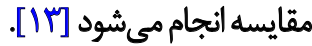

در اين مطالعه از طبقهبندى إرائهشده در دستور كار يُؤوهش در

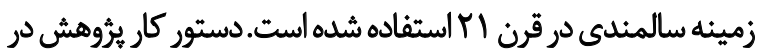

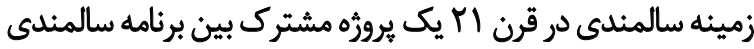

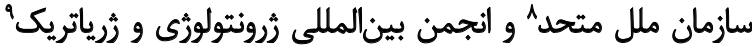

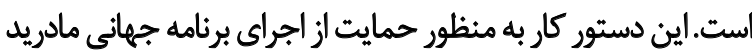

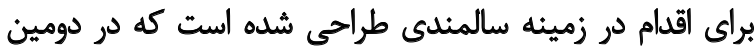

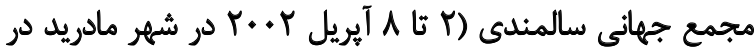

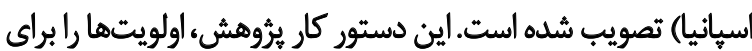

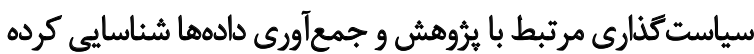

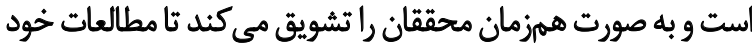

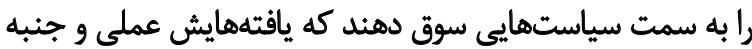

7. Research Agenda on Ageing for the $21^{\text {st }}$ century (RAA-21)

8. United Nations Programme on Ageing (UNPoA)

9. International Association of Gerontology and Geriatrics (IAGG)
بررسى شودمهنيكوفّ اولين بار لغت ثرونتولورثى را در سال

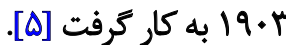

مى توان كفت كه رشد سريع سالمندشناسى از قرن بيستم آغاز

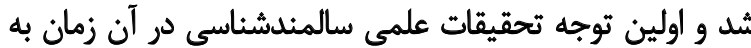

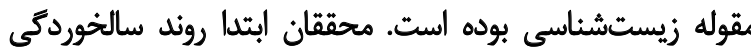

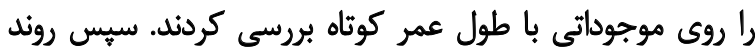

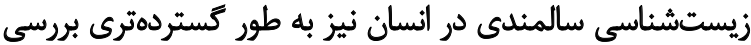

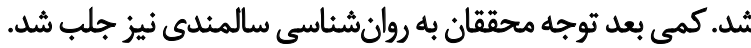

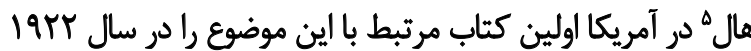

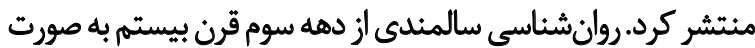

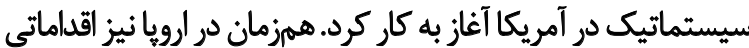

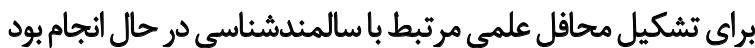

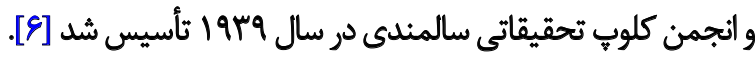
بعد از كذشت بيش از •ه سال از شروع به كار سيستماتيك علم

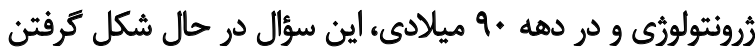

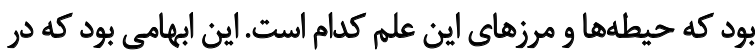

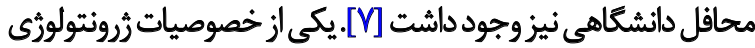

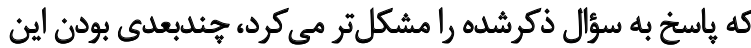

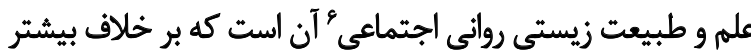

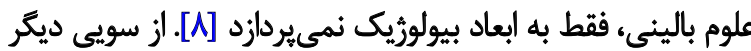

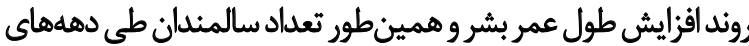

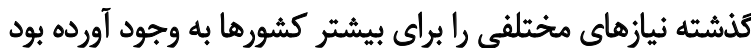

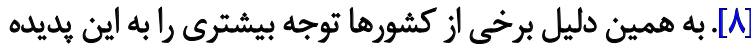

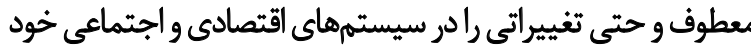

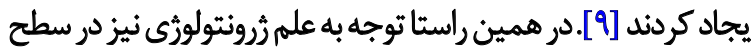

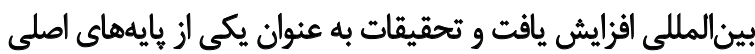

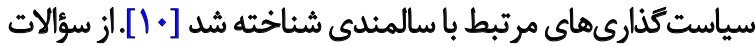

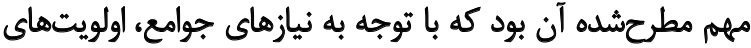

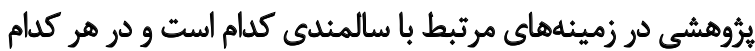
از حيطههاى سالمندشناسى به جه موضوعاتى بايد بيشتر توجه شودي

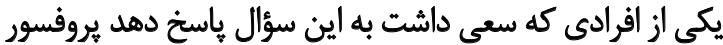

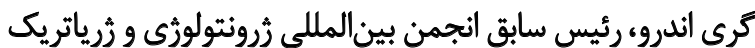

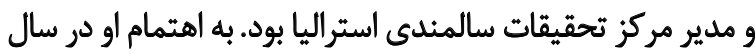

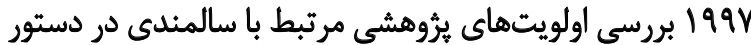

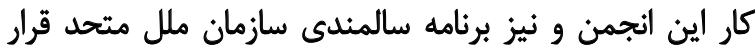

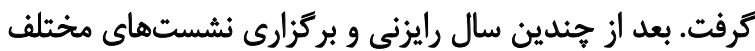

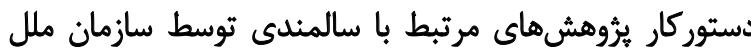

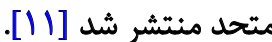

كشور ايران نيز جندان ازيديده سالمندى دور نمانده است.تغييرات

4. Metchnikoff

5. Hall

6. Biopsychosocial 
(اولويت تحقيقاتى) نيز مشخص مي شد. دادهها وارد نسخه ل1 ( نرمافزار

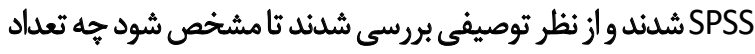

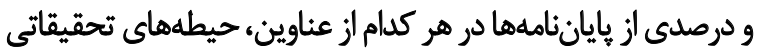

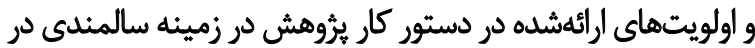

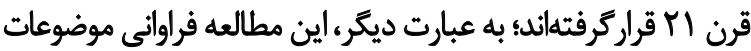
مطالعهشده رادر اين سه سطح بررسى مئى بكند.

نتايج به صورت كمّى جمعبندى و كَزارش شد. برخى از يرويوزالها

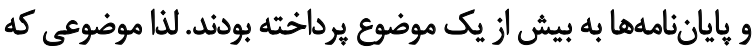

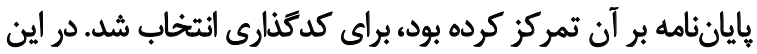

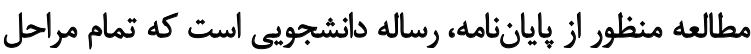

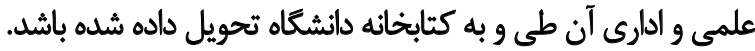

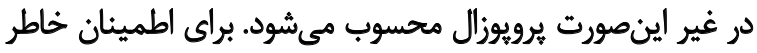

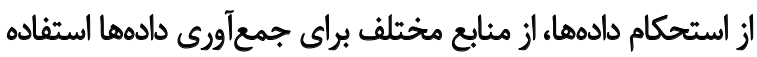

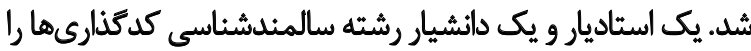

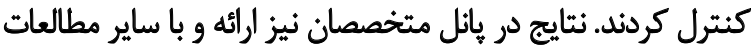

مشابه مقايسه شد.

يأقتهما

در اين مطالعه كه به منظور بررسى عناوين پاياننامههاي مرتبط

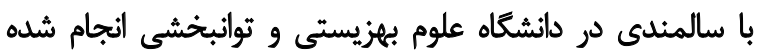

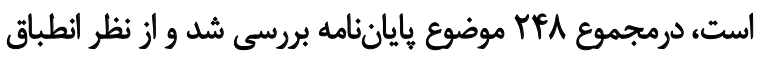

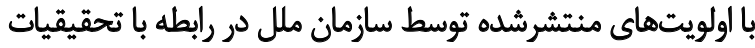

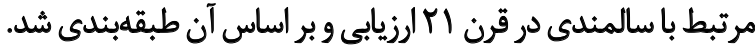

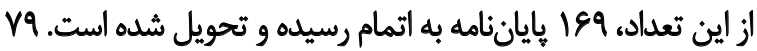

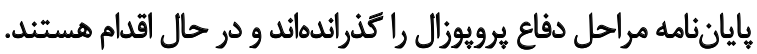

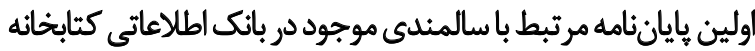

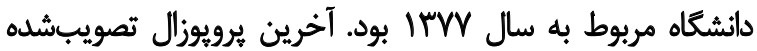

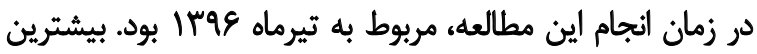
تعداد بايان

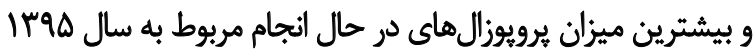

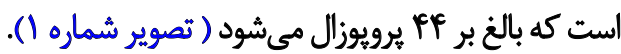

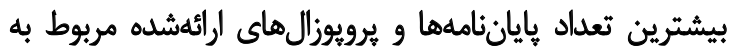

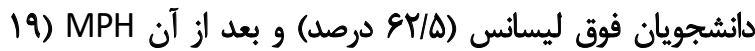

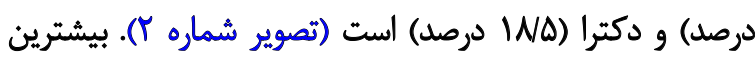

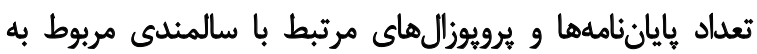

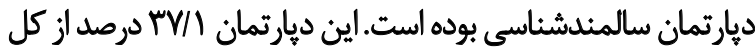

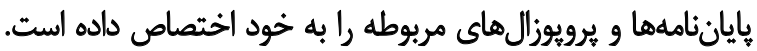

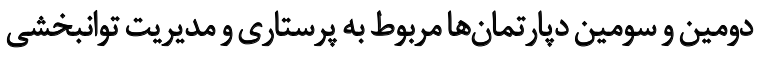

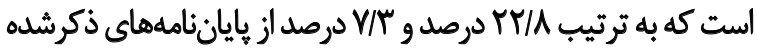
را الرائه دادهاند (تصوير شماره بان).

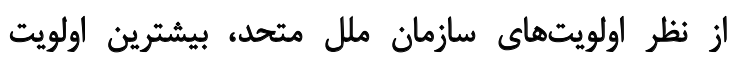

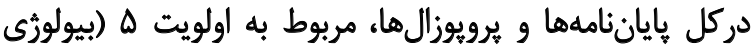

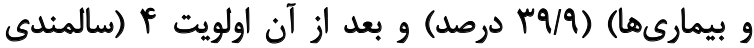

كاربردى واقعى داشته باشد. اين دستور كار بعد از جلسات مشاورهاى

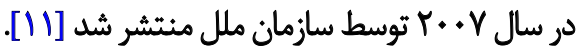
دستور كار يرؤهش در زمينه سالمندى در قرن البدرمجموع

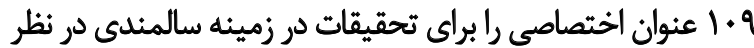

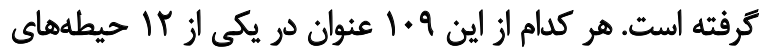

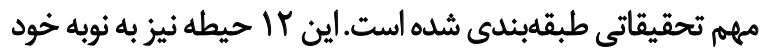

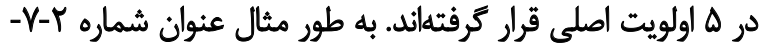

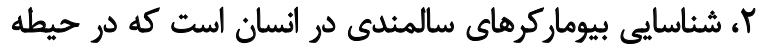

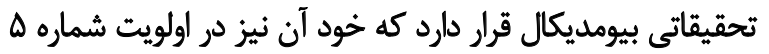

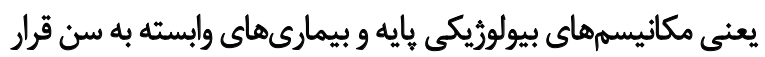
مي [11] [11] اولويتهاي اصلى يثروهشى دستور كار بثروهش در زمينه سالمندى در قرن ال المامل موارد زير است:

اولويت ا : رابطه ميان جمعيت در حال بيرشدن و توسعه اجتماعى

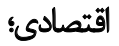
اولويت Y: اقدامات و انتخابهاى موجود براى بايدارى امنيت مادى

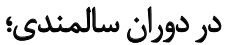
اولويت "ا: تغيير ساختار خانواده، سيستمهاى انتقال بيننسلى وتحركات نوظهور خانوادگى و مؤسسهاى؛ اولويت f: شاخصهاي سالمندى سالم؛ اولويت ه: مكانيسمهاي بيولوزيكى پايه و بيمارىهاي وابسته بئ سن؛ اولويت \&:كيفيت زندكى و سالمندى در شرايط فرهنكى، اقتصادى، اجتماعى و محيطى مختلف.

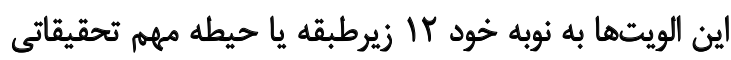

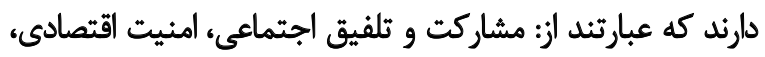

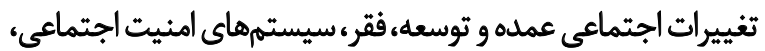

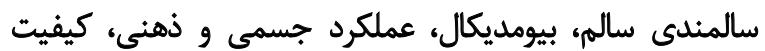

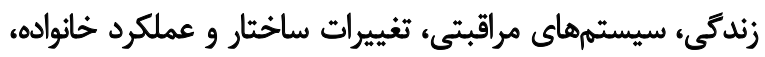

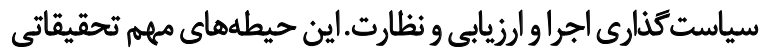

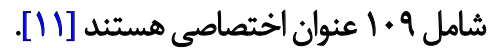

در اين مطالعه، اين تقسيمبندى به صورت طبقهبندى اوليه

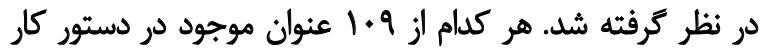

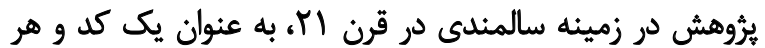

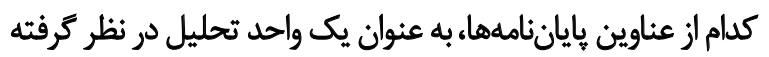

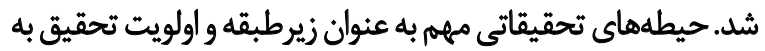

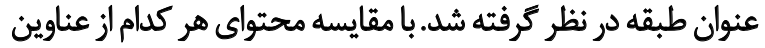

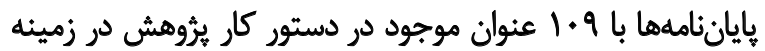

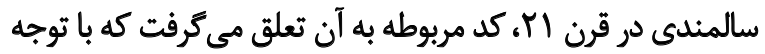
به تقسيميندى ذكرشده، زيرطبقه (حيطه مهم تحقيقاتى) و طبقه 
جدول 1. فراوانى ياياننامهها برحسب حيطه تحقيثاتى

\begin{tabular}{|c|c|c|c|c|}
\hline درصد تجمعى & درصد معتبر & درصد & فراوانى & حيطه تحقياتى \\
\hline$r / r$ & $r / r$ & $r / r$ & $\wedge$ & طبقهبئدى نشله \\
\hline$I T / N$ & $1+10$ & $1+/ \Delta$ & rq & مشاركت و تلفيق اجتماعى \\
\hline $1 \otimes / T^{\prime}$ & $1 / 8$ & $1 / 8$ & f & امنيت اقتصادي \\
\hline $1 \Delta / N$ & $\cdot /{ }^{e}$ & $\cdot /{ }^{\circ}$ & 1 & فقر \\
\hline Wo & $r / A$ & $r / A$ & $\checkmark$ & سيستمهاى امنيت اجتماعى \\
\hline MV/O & $19 \%$ & $19 /$ & PV & 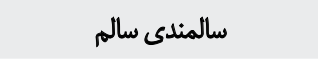 \\
\hline$\Delta \& 1 \Delta$ & 19. & $19 \%$ & Pr & 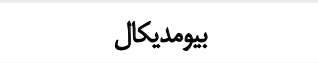 \\
\hline VNY & $\mathrm{r} / \mathrm{A}$ & $r / A$ & ap & عملكرد جسمى و ذهنى \\
\hline$A V / q$ & $9 / N$ & $9 / V$ & ri & كيفيت زندكى \\
\hline $94 / 1$ & $\Delta / r$ & $\Delta / r$ & ir & سيستمهاى مراقبتى \\
\hline$q / p$ & $M / r$ & $m / K$ & $\wedge$ & تغييرات ساختار و عملكرد خانواده \\
\hline \multirow[t]{2}{*}{$1 .+1+$} & $r / \varepsilon$ & $r / s$ & 9 & سياست كذارى اجرا، ارزيائى و \\
\hline & $1 .$. & $1 .$. & reA & جمع - لمع \\
\hline
\end{tabular}

\section{L}

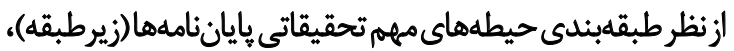

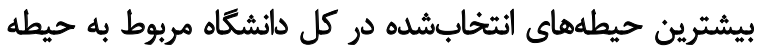

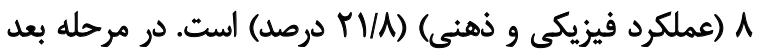

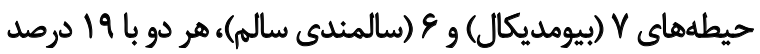
قرار ترفته است (جدول شماره () ).

در اين سطح هيج يايان امنه و يا يرويوزالى در زيرطبقه تغييرات

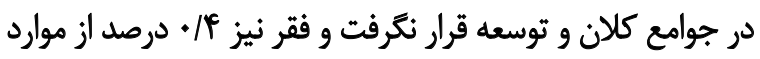

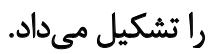

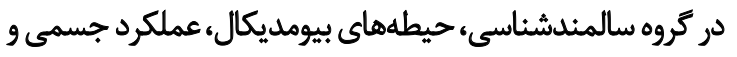

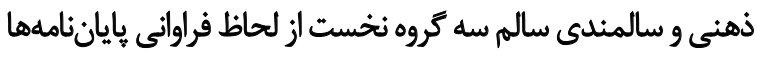

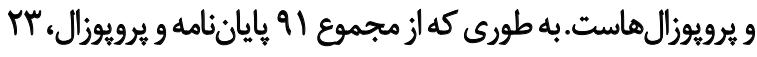

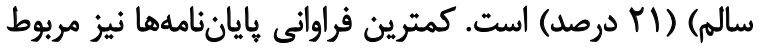

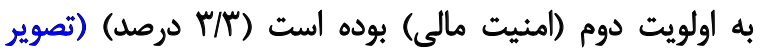

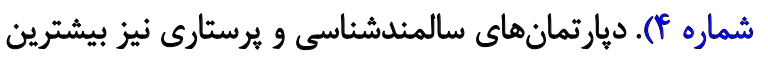

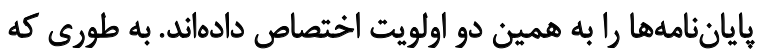

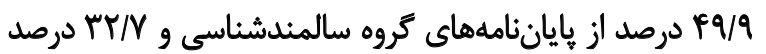

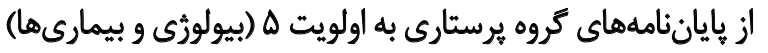

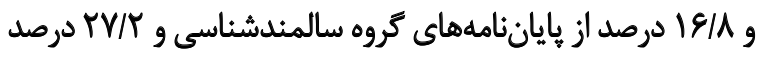

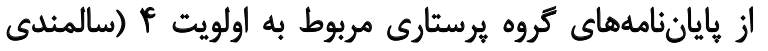

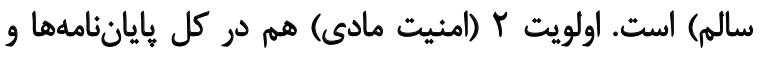

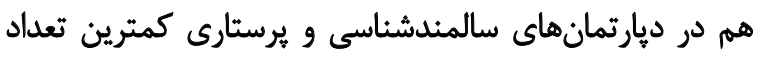

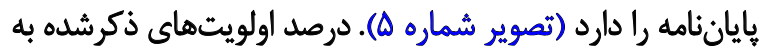
تفكيك براى هر كدام از ديار تمانها در تصوير شماره 8 آمده است.

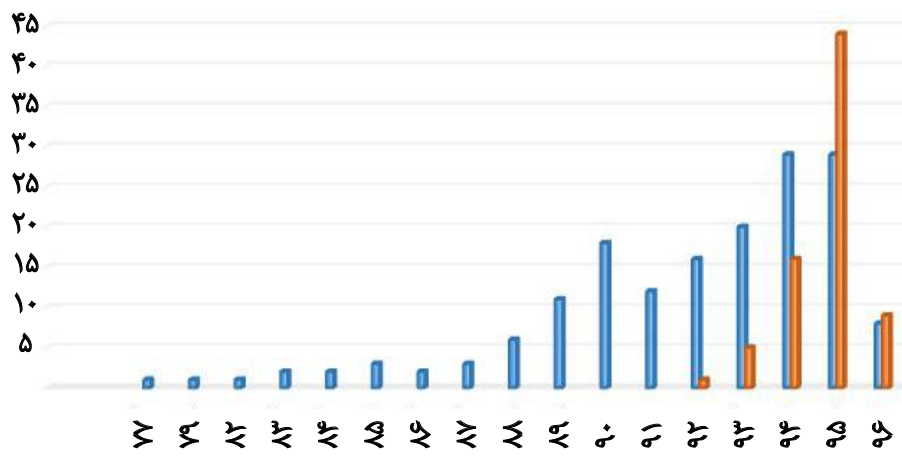




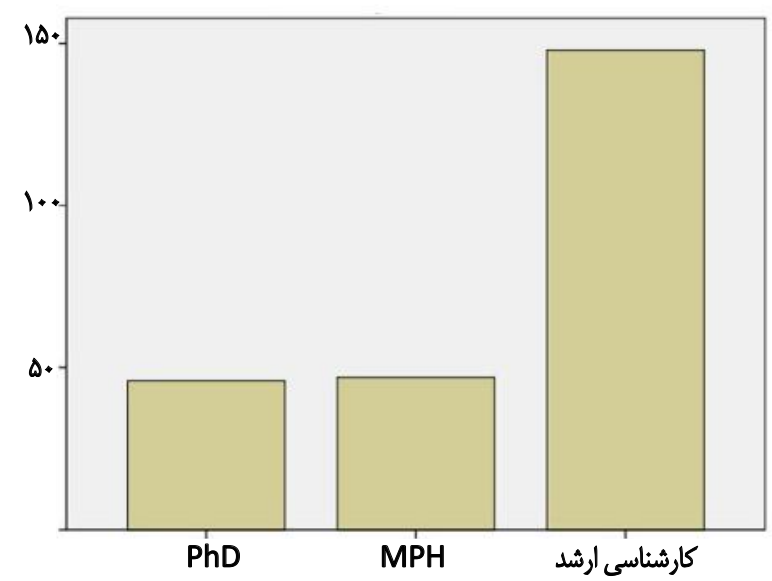

تصوير Y. تعداد ياياننامهها بر اساس مقطع تحصيلى

هايان نامه هاي مرتبط به سالمندى (f مورد) مرتبط به حيطه سالمندى

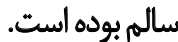

در كروه زثتيك، يك ياياننامه مرتبط با سالمندى در دسترس

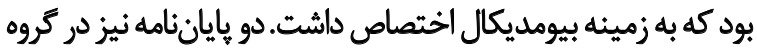

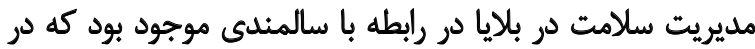

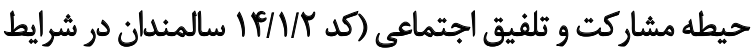

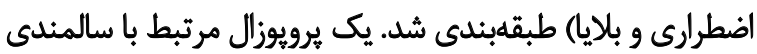

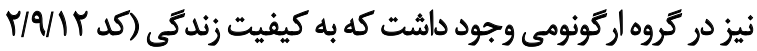

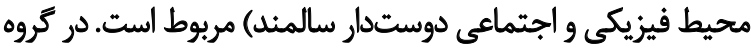

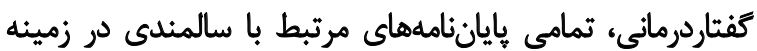

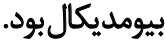
در سطح كدها و يا عناوين اختصاصى مطالعهشده، بهداشت روانى

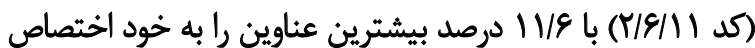

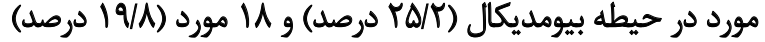

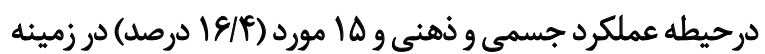

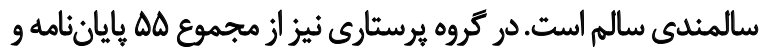

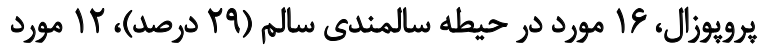

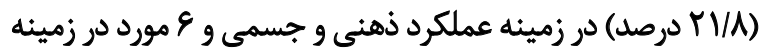
بيومديكال است (9/ · ا درصد) (تصوير شماره V).

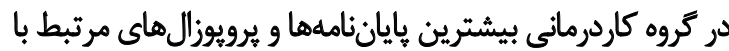

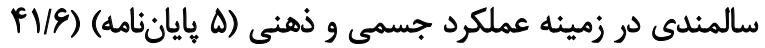

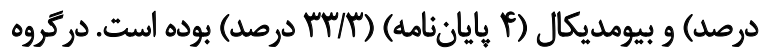

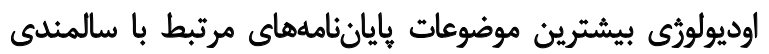

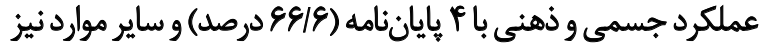
در حيطه بيومديكال بوده است.

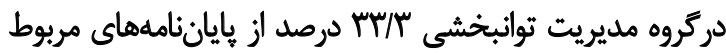

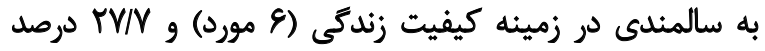

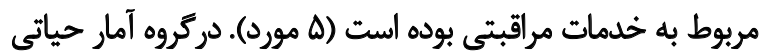

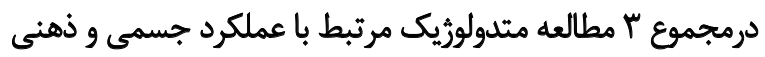

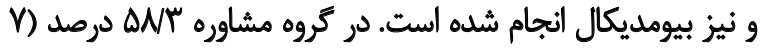

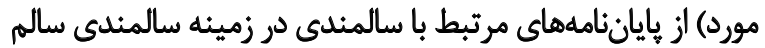
أنتخاب شده است.

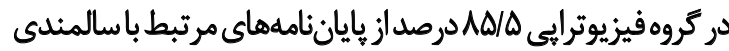

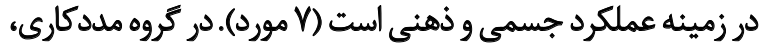

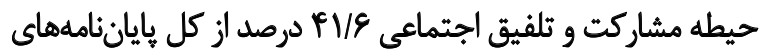

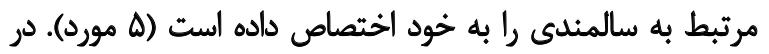

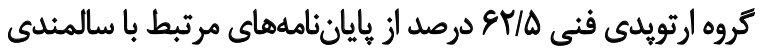

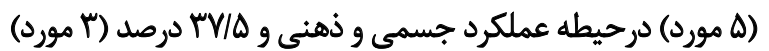

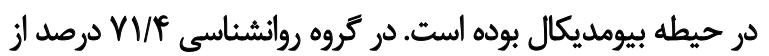

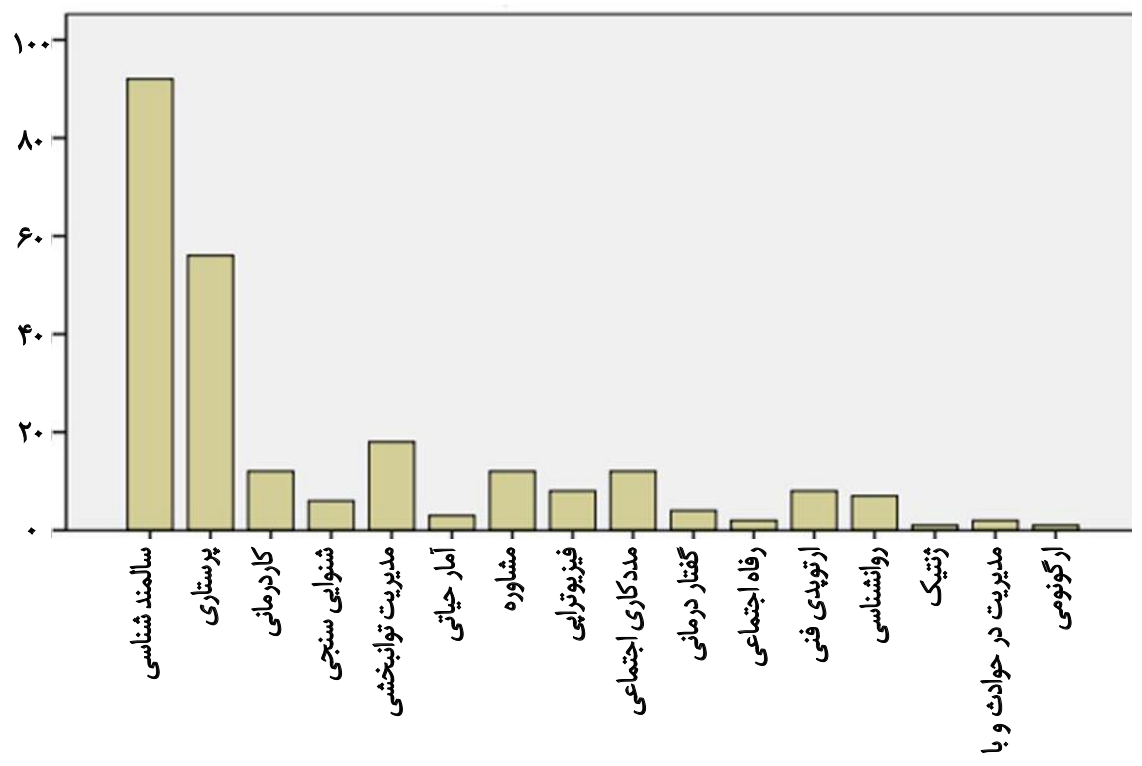




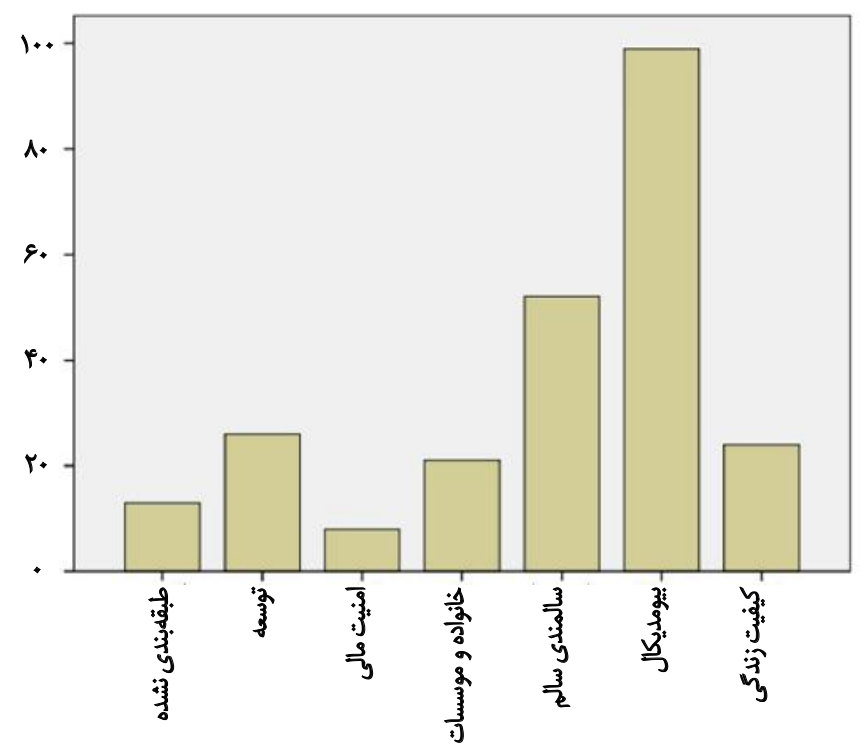

L

تصوير P. فراوانى باياننامها بر حسب اولويتبندى دستور كار بروهش در زمينه سالمندى در قرن

هايان نامهالى مرتبط با سالمندى در سال هاى اخير رشد قابل توجهى

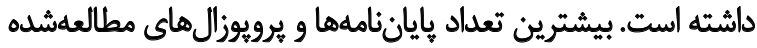

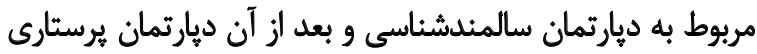

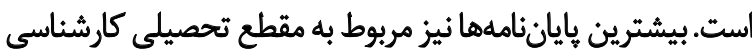
ارشد و بعد از آن به ترتيب MPH و دكتراست.

سه اولويت ثروهشى اول در دستور كار يُوهش در زئ زمينه

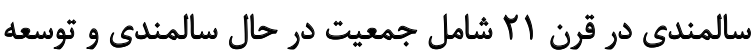

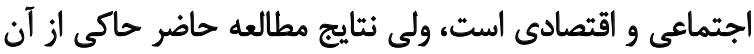

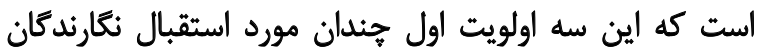

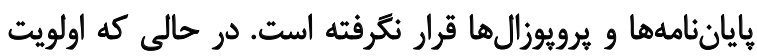

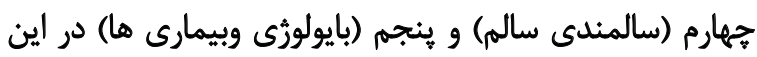

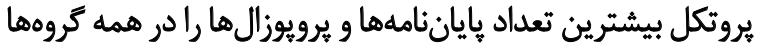

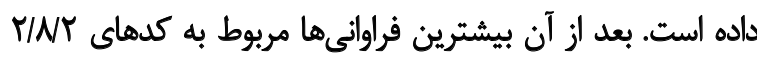

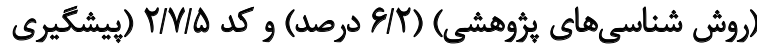

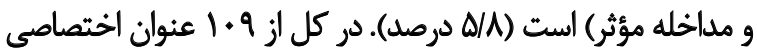

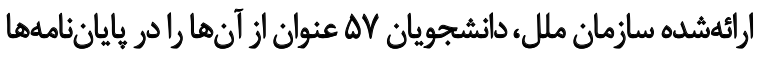

استفاده كرند.

$$
\text { ب }
$$

در اين مطالعه عناوين يايان نامههاو يرويوزال هاي دانشجويى مرتبط

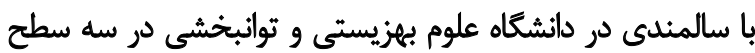

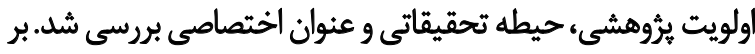

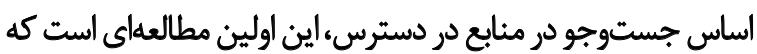

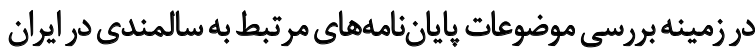
انجام شده است. نتايج مطالعه انجامشده حاكى از آن است كه تعدادئ

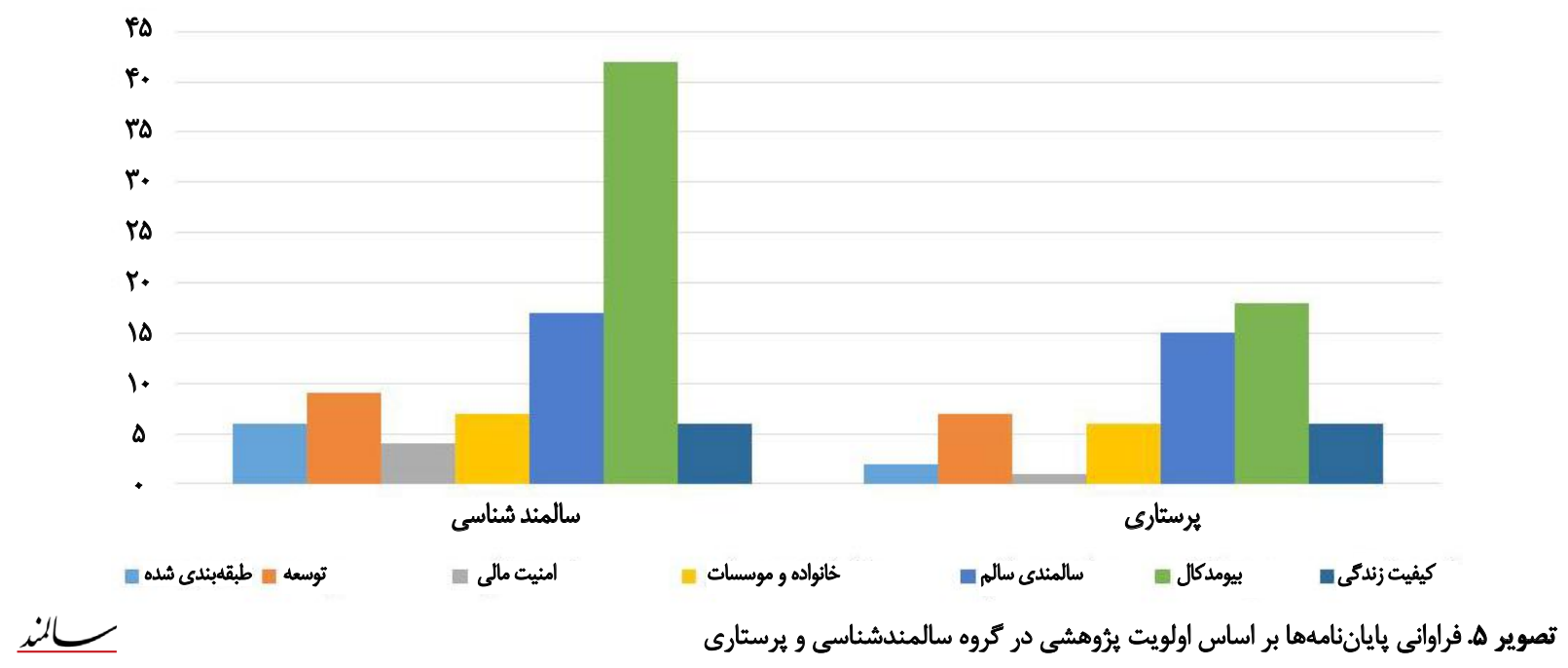




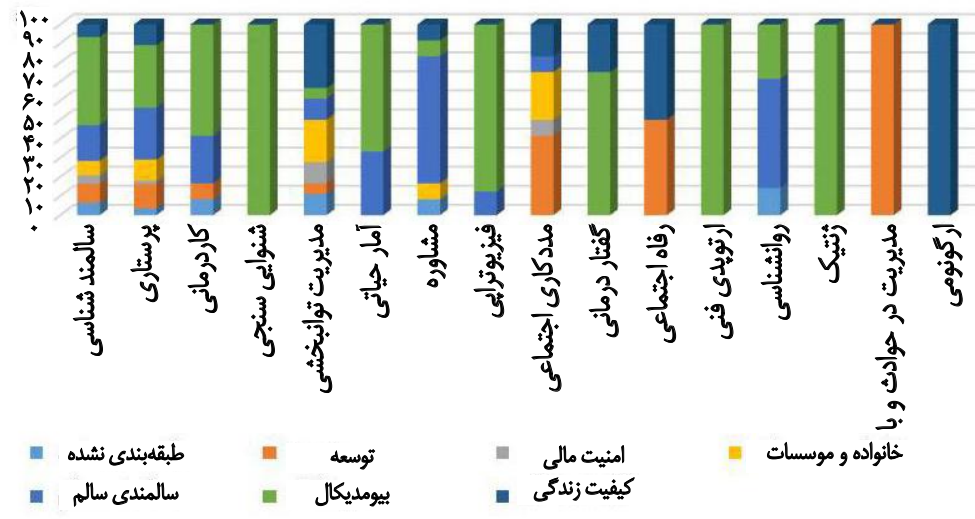

L

نيازهاى ملى شكل كرفته باشد. بهاهرحال، تأييد اين فرضيهها نيازمند

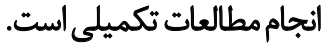

اين كرايش در سطح حيطههاى مهم تحقيقاتى و نيز در سطح

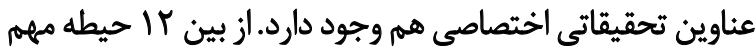

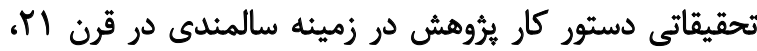

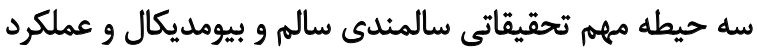

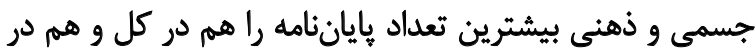

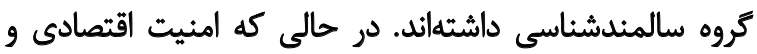

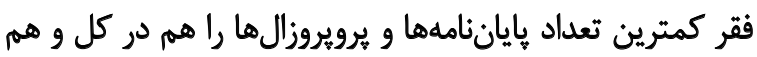

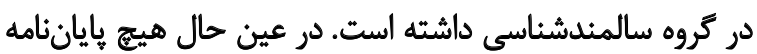

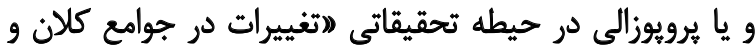

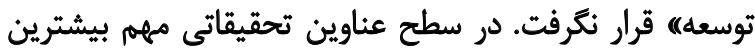

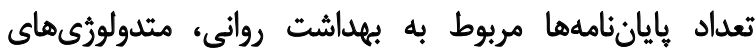

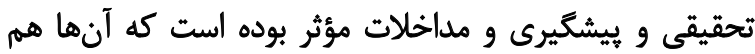

تصوير و. درصد اولويت هاى برُوهشى در هر كدام از ديارتمان ها و نيز در گروه سالمندشناسى به خود اختصاص داده است. اين

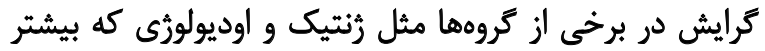

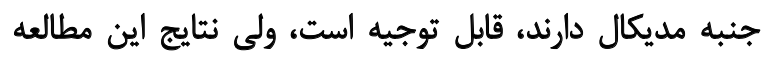

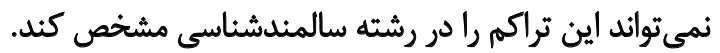
ثيروهش هاى تكميلى براى شناخت دليل كم بودن تعداد مطالعات

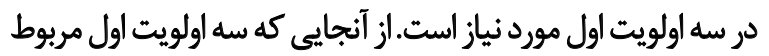

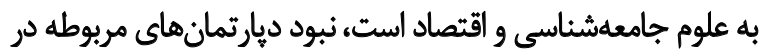

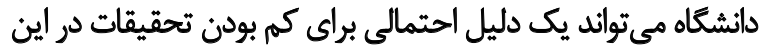

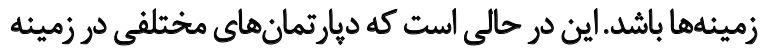

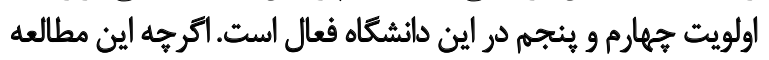

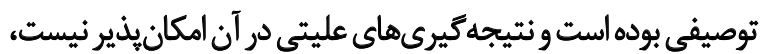

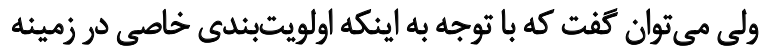

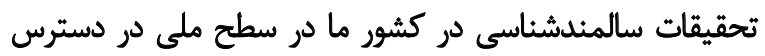

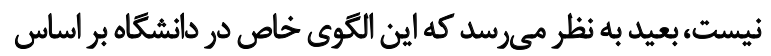

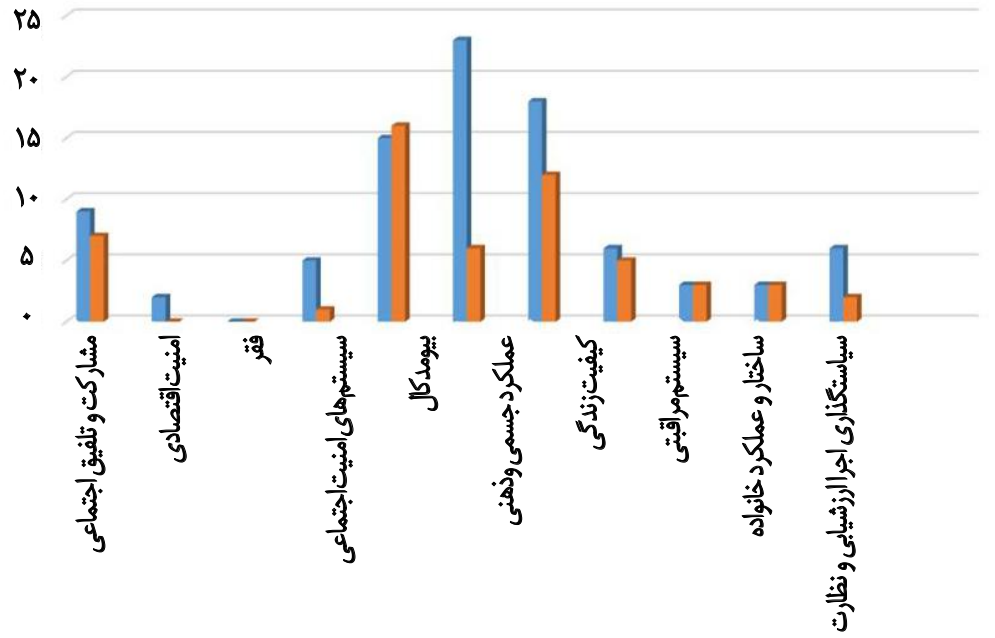

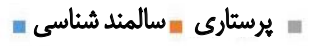
تصوير ل. فراوانى باياننامهها بر اساس حيطه تحقيقاتي در دو كروه سالمثدشناسى و يرستارى 
تلفيق و مشاركت اجتماعى، كمتر در انتخاب موضوعات ياياننامهها

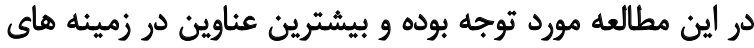

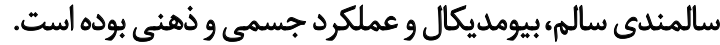

\section{نتيجهئيرىنهايي}

در دستور كار يثوهش در زمينه سالمندى در قرن الج بين

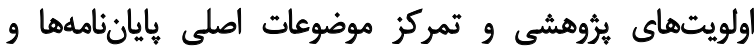

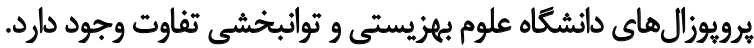

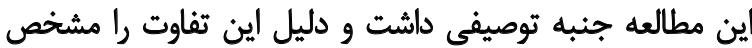

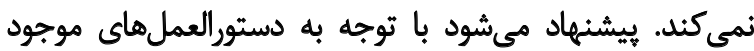

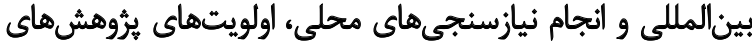

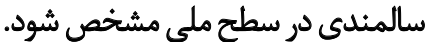

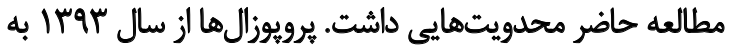

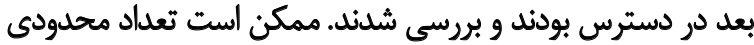

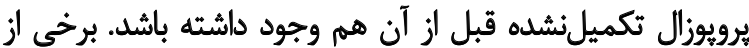

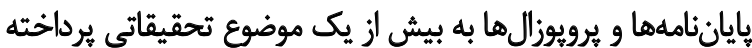

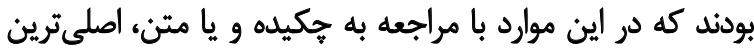

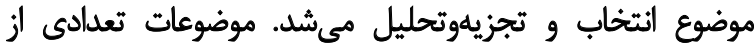

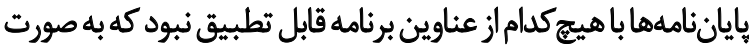
طبقلهبندينشده، كدكذاري شاندند.

ملاحظات اخلاقى

\section{ييروى أز اصول اخلاق بثروهش - ميث}

در اين مطالعه به منظور حفظ اصول اخلاق يرؤهش از ذكر نام اشخاص و عنوان دقيق يايان نامهها خوددارى شده است.

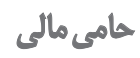

اين مقاله بركرفته از يروزه تحقيقاتى با شماره

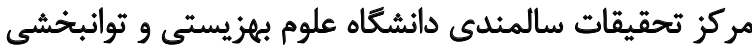

$$
\text { تصويب شده است. }
$$

$$
\text { تقارض مثأع }
$$

بنا به اظههارنظر نويسندكان، اين مقاله تعارض منافع ندارد.

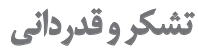

نكارندكان مقاله لازم مى دانند از همكارى و هميارى جناب آقاى

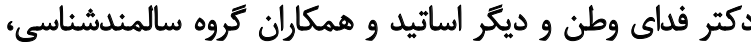

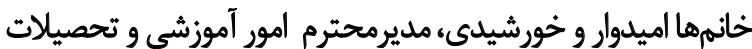

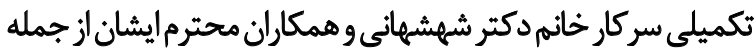

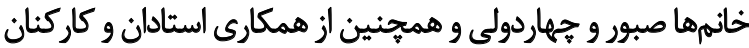

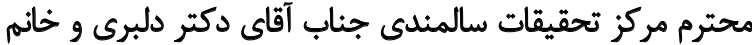

$$
\text { روستايى تشكر كنيند. }
$$

زيرشاخههاى سه حيطه مهم تحقيقانى با فراوانى بيشتر هستند

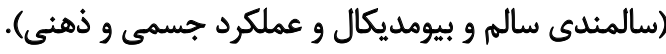

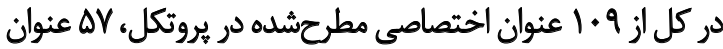

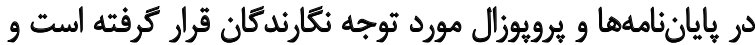

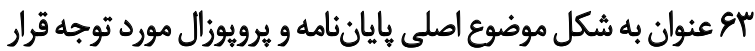

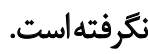

تحقيقات مشابه جندانى در اين زمينه در دسترس نيست.بر اساس

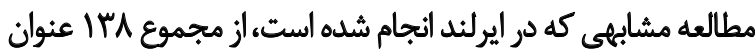

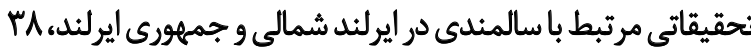

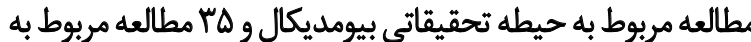

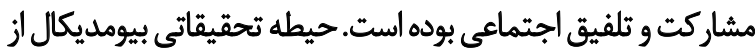

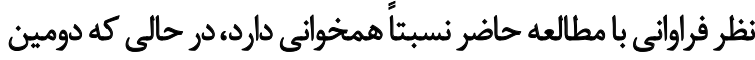

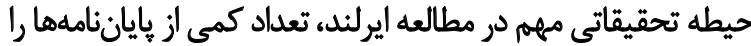

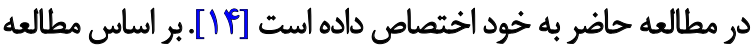

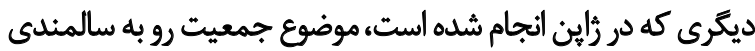

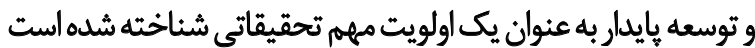

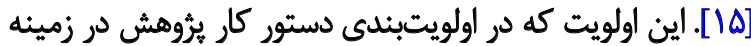

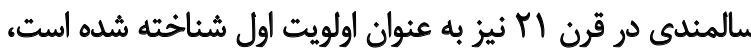

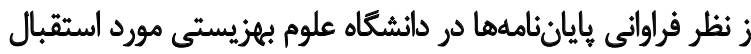
جندانى نبوده است.

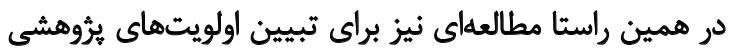

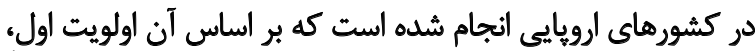

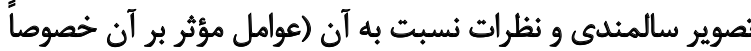

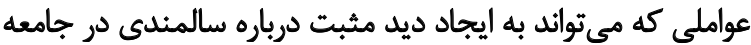

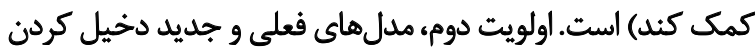

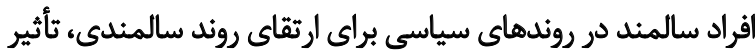

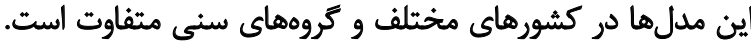

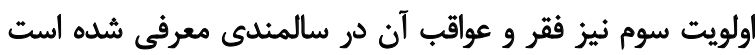

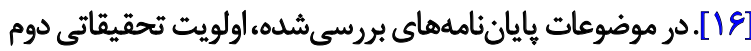

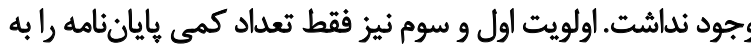
خود اختصاص داده است.

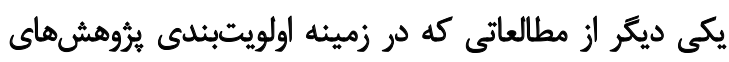

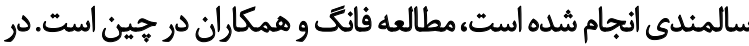

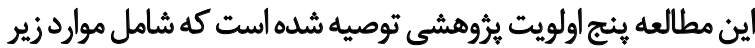

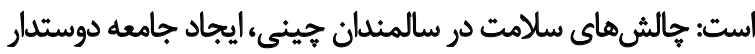

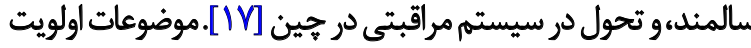
اول مثل بيمارىهاى غيرمسرى و بهداشت روانى كه در مطالعه فئن إنى

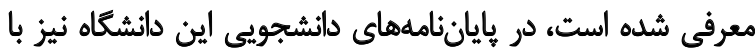

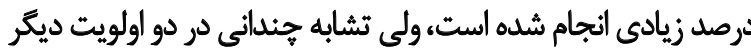

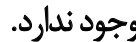

با توجه به موارد ذكرشده به نظر ميىرسد موضوعات يثروهشى در

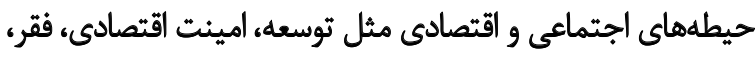




\section{References}

[1] Mulley G. A history of geriatrics and gerontology. European Geriatric Medicine. 2012;3(4):225-7. [DOI:10.1016/j.eurger.2012.06.007]

[2] Morley JE. A brief history of geriatrics. The Journals of Gerontology Series A: Biological Sciences and Medical Sciences. 2004; 59(11):1132-52. [DOI:10. 1093/gerona/59.11.1132]

[3] Nozad A, Naseri M, Safari MB, Al Ahadi AA, Ghaffari F. Food reduction in Avicenna's view and related principles in classical medicine. Iranian Red Crescent Medical Journal. 2016; 18(6):e25760. [DOI:10. 5812/ircmj. 25760] [PMID] [PMCID]

[4] Howell TH. Avicenna and his regimen of old age. Age and Ageing. 1987; 16(1):58-9. [DOI:10. 1093/ageing/16. 1. 58] [PMID]

[5] Cole TR, Sierpina M. Humanistic gerontology and the meaning (s) of aging. Gerontology: Perspectives and Issues. 2007; 245-63.

[6] Tibbitts C. Introduction-social gerontology-origin, scope and trends. International Social Science Journal. 1963; 15(3):339-54.

[7] Achenbaum WA, Levin JS. What does gerontology mean. The Gerontologist. 1989; 29(3):393-400. [DOI:10. 1093/geront/29. 3. 393]

[8] Hooyman NR, Kiyak HA. Social Gerontology: A Multidisciplinary Perspective. Boston: Allyn \& Bacon; 2011.

[9] Bengtsson T, Scott K. Population ageing: A threat to European welfare. In S. Gustavsson, L. Oxelheim, L. Pehrson (Eds.), How Unified Is the European Union; Berlin: Springer; 2009. [DOI:10. 1007/978-3-540-95855-0_8]

[10] United Nations. Madrid International Plan of Action on Ageing; Report of the Second World Assembly on Ageing. New York: United Nations; 2002

[11] United Nations. Research Agenda on Ageing for the $21^{\text {st }}$ Century. New York: United Nations; 2007.

[12] Danial Z, Motamedi M, Mirhashemi S, Kazemi A, Mirhashemi AH. Ageing in iran. Lancet. 2014; 384(9958):1927. [DOI: 10.1016/ S0140-6736(14)62278-9]

[13] Elo S, Kyngäs H. The qualitative content analysis process. Journal of Advanced Nursing. 2008; 62(1):107-15. [DOI:10. 1111/j. 1365-2648. 2007. 04569. x]

[14] Centre for Ageing Research and Development in Ireland Mapping Research in Ireland. Against the UN Research Agenda on Ageing for the $21^{\text {st }}$ Century (2007 Update) [Internet]. 2017 [Updated 2017 September 18]. Available from: www.cardi.ie/userfiles/ UN\%20mapping\%20framework\%206\%20Jan\%202009.doc.

[15] Kudo S, Mutisya E, Nagao M. Population aging: An emerging research agenda for sustainable development. Social Sciences. 2015; 4(4):940-66. [DOI:10. 3390/socsci4040940]

[16] Andrews G, Sidorenko A, Gutman G, Gray J, Anisimov V, Bezrukov $\mathrm{V}$, et al. Research on ageing: Priorities for the European region. Успехи геронтологии. 2006; 18:7-14.

[17] Fang EF, Scheibye-Knudsen M, Jahn HJ, Li J, Ling L, Guo H, et al. A research agenda for aging in China in the $21^{\text {st }}$ century. Ageing Research Reviews. 2015; 24(Pt B):197-205. [DOI:10.1016/j. arr.2015.08.003] 